\title{
Development of Dietary Information Literacy Scale for Competition (DILS-C) in Japanese College Athletes
}

\author{
Yuya KAKUTANi ${ }^{1}$, Mayu MURATA ${ }^{2}$, Akane KoIWA ${ }^{2}$, Miho ONO ${ }^{3}$, \\ Ikuko SASAHARA ${ }^{3}$ and Naomi OMI ${ }^{4, *}$ \\ ${ }^{1}$ Faculty of Health and Nutrition, Osaka Shoin Women's University, 4-2-26 Hishiya-nishi, \\ Higashi-Osaka, Osaka 577-8550, Japan \\ ${ }^{2}$ Graduate School of Comprehensive Human Science, University of Tsukuba, 1-1-1 Tennodai, \\ Tsukuba, Ibaraki 305-8574, Japan \\ ${ }^{3}$ Institute of Food Sciences $\mathcal{E}$ Technologies, Ajinomoto Co., Inc., 1-1 Suzuki-cho, \\ Kawasaki-ku, Kawasaki, Kanagawa 210-8681, Japan \\ ${ }^{4}$ Faculty of Health and Sport Sciences, University of Tsukuba, 1-1-1 Tennodai, \\ Tsukuba, Ibaraki 305-8574, Japan
}

(Received March 12, 2020)

\begin{abstract}
Summary This study aimed to examine the scale for reliability and validity of the dietary information literacy scale for competition (DILS-C) in college athletes. This cross-sectional study was performed using a self-report questionnaire for college athletes who belong to the club of the university located in Ibaraki prefecture, Japan, from October to December 2014. The final sample comprised 953 college athletes, 684 males and 269 females, aged 18 to $22 \mathrm{y}$. Following item selection by exploratory factor analysis, the scale's reliability and validity were examined via internal consistency and confirmatory factor analysis. Furthermore, a retest for 376 athletes was conducted at about 3-wk intervals. Factor analysis of literacy measure indicated that the scale consists two sub-scales-communicative literacy and critical literacy. The Cronbach's $\alpha$ coefficient assessing the internal consistency reliability was acceptable (communicative literacy $=0.84$, critical literacy $=0.79$ ). Excellent goodness-offit indices of communicative and critical literacy were obtained by confirmatory factor analysis $(\mathrm{GFI}=0.95$, AGFI $=0.92, \mathrm{CFI}=0.95$, RMSEA $=0.08)$. Retest reliability was within an allowable range (communicative literacy ICC $=0.52$, critical literacy ICC $=0.50$ ). The present study suggested that the reliability and factorial validity were confirmed in the DILS-C in college athletes.
\end{abstract}

Key Words communicative literacy, critical literacy, students, sports, Japan

Nutrition knowledge and education remain salient in providing understanding and skills required for competitive college athletes to undertake appropriate eating behaviors (1). Moreover, the lower the athletes' nutritional knowledge, the poorer their eating habits (2). Therefore, college athletes should acquire and use nutritional knowledge to adopt certain dietary behaviors for improving performance. Many college athletes obtain nutritional information from their coaches or athletic trainers, who are not experts like dietitians $(3,4)$, and coaches and athletic trainers have been reported to tend to have poor nutritional knowledge $(2,4)$. Furthermore, that dietary behavior remains stagnant in those who cannot obtain nutritional information has also been reported (5). Therefore, differences seem to occur in dietary behaviors for high performance according to whether college athletes obtain accurate nutritional information. In these circumstances, college athletes need to obtain and make effective use of accurate information.

In addition, health literacy represents cognitive and

\footnotetext{
*To whom correspondence should be addressed.
}

E-mail: omi.naomi.gn@u.tsukuba.ac.jp social skills that determine individuals' motivation and ability to access, understand, and use information to promote and maintain good health (6). Health literacy implies the achievement of a level of knowledge, personal skills, and confidence to act to improve personal and community health by changing personal lifestyles and living conditions (6). Moreover, health literacy can be divided into three levels, i.e., functional, communicative, and critical: functional literacy-sufficient basic skills in reading and writing to be able to function effectively in everyday situations; communicative literacymore advanced skills to participate actively in every activities, to extract information and derive meaning from different forms of communication, and to apply new information to changing circumstances; critical literacy-more advanced skills to analyze information critically and to use this information to exert greater control over life events and sitations (7). Previous studies have reported a link between the level of health literacy and health outcome $(6,8,9)$. By improving people's access to health information and their capacity to use it effectively, health literacy becomes critical to empowerment (6). Therefore, we need to raise the literacy level in order that people understand health information cor- 
rectly and make effective use of information.

Furthermore, in addition to health literacy for general health, literacy scales on nutritional and dietaryrelated information have been developed for various populations $(5,10,11)$. A specific scale of food information is needed because the type and level of literacy required for acquisition depends on the type of information. Since many of the previously reported measures have been developed for the prevention and treatment of diseases, it is difficult for these measures to adequately evaluate the literacy of athletes aiming for maximum performance. Therefore, a scale for college athletes, specializing in diet and nutrition for maximum performance, is needed. College students can read and write basically, and previous health literacy research reported that college students had adequate levels of functional literacy, which is a basic ability (12). If college athletes have problems in accessing, understanding, and using dietary information, they are about communicative or critical literacy, which are developmental abilities, not about functional literacy. Therefore, in this study, we forcused on communicative literacy and critical literacy.

Based on the health literacy concept, increasing literacy on diet to maximize college athletes' performance can lead to using dietary information effectively and maintaining dietary behavior for athletic performance. Moreover, health literacy contributes to college athletes' acquisition of dietary information by selecting people with low literacy for nutritional information and thus raising literacy itself. Clues for promoting support of utilizing literacy can be obtained by investigating transmission methods so that people with low literacy can recognize dietary information and by preparing easyto-understand dietary information. However, no report exists on a dietary information literacy scale for competition (DILS-C) in college athletes.

Therefore, this study was conducted to develop communicative and critical literacy for a dietary information literacy scale for competition in Japanese college athletes and to examine the scale's reliability and validity.

\section{MATERIALS AND METHODS}

Participants and study design. This cross-sectional study was performed with a self-written questionnaire for college athletes who belonged to the club of University of Tsukuba (Ibaraki, Japan), from October to December 2014.

The survey method was set as a collective survey method for each club. We explained to the representative of the target club about the significance and purpose of the research in writing and verbally. After obtaining consent from the representative, the significance and purpose of the research was explained to each of the members of each club verbally. An examiner explained the general purpose and outline of the survey to participants who were college athletes belonging to the club of the university. Details of the study design and participant characteristics have been reported elsewhere (13).

A total of 1,043 students answered the questionnaires. Subjects for whom data regarding sex (gender), literacy items, resident type or action skills of information utilization were missing $(n=90)$ and those aged over 23 y $(n=33)$ were excluded (students who overlap both two exclusion criteria: $n=33$ ). The final sample comprised 953 students, including 684 males and 269 females, aged $18-22$ y (effective response rate $=91.4 \%$ ).

For the questionnaire's temporal stability, we used the retest method. The DILS-C was examined through correlation of pre- and post-scores with intra-class correlation. We randomly extracted target groups from among all groups that did not have competitions before and after the survey, requested cooperation for participation, and obtained cooperation from 15 organizations, that is, 376 people. We conducted the retest from October to December 2014, at about 3-wk intervals.

This study was conducted after receiving approval from the research ethics committee of the Faculty of Health and Sport Sciences, University of Tsukuba (No. 26-49). This study was performed in accordance with the Declaration of Helsinki.

\section{Measures.}

Dietary information literacy scale for competition (DILS-C): The DILS-C was adapted from the items of communicative and critical literacy in the Health Literacy Scale (HLS-14) to measure general health literacy (14), and the items of healthy eating literacy (5). This adaptation of DILS-C was to specialize in dietary information for competition, and replaced "doctor" with "coach." This adaptation of DILS-C was carried out through discussions with dietitians, and considerations by the authors. We rectuied 2 dietitians with experience supporting various college athletes, such as female athletes and team sports athletes. The DILS-C is shown in Table S1 (Supplemental Online Material). The DILS-C asked about communicative literacy (six items) and critical literacy (six items). Regarding communicative literacy, the subjects were asked the following question: "When you read the dietary information for competition, what do you usually think about the following items, please circle the number of the option that applies to you?" Regarding critical literacy, the subjects were asked the following question: "Please circle each applicable number in the following items for dietary information for competition you saw or heard." We used the five-point scale; score 1: "I do not think so at all," score 2: "I do not think so much," score 3: "Neither," score 4: "Well so," score 5: "I think so much."

Action skills of information utilization: We used the action skills of information utilization developed by Takahira et al. (15) as an indicator of convergent validity. The subjects were asked the following question: "We ask about your way of thinking life, please circle each applicable number." and we represented 54 items that are composed of six factors (collecting ability, judgment, power of expression, processing ability, creativity, transmission ability). We used the seven-point scale; score 1: "Not applicable at all," score 2: "Almost not applicable," 
score 3: "Not much applicable," score 4: "Neither," score 5: "Slightly applicable," score 6: "Applicable well," score 7: "very well applicable." Twenty-seven items which are invert scale are as follows; score 1: "Very well applicable" to score 7: "Not applicable at all." For the scoring, simple addition of each subscale was performed, and the scores of all 54 items were summed up as "action skills of information utilization." Action skills of information utilization involve the "ability to collect, judge, express, process, create the necessary information on an individual basis, and to transmit based on the status of the receiver while properly utilizing information means according to the tasks and goals" (15).

Healthy eating literacy: We used healthy eating literacy developed by Takaizumi et al. (5) as an indicator of convergent validity. The subjects were asked the following question: "Do you think that you can find and use own health related dietary information if you need? Please circle each applicable number." and we represented five items. We used the five-point scale; score 1: "I do not think so at all," score 2: "I do not think so much," score 3: "Neither," score 4: "Well so," score 5: "I think so much," and the average score of five items was taken as a scale score.

Data analysis. The average score and standard deviation were calculated in the item analysis. We confirmed the ceiling (mean $+\mathrm{SD} \geqq 5$ ) or floor (mean $-\mathrm{SD} \leqq 1$ ) effect for each items of DILS-C, but there was no applicable items. Next, exploratory factor analysis based on the method of maximum likelihood promax rotation was performed, and we deleted items with factor loadings less than 0.4 and, then, again performed factor analysis. To verify the model's validity, confirmatory factor analysis was conducted with reference to the relevance index with SPSS Amos (22, IBM Corp, Armonk, NY). We adopted the following as indicators of goodness of fit: goodness of fit index (GFI), adjusted GFI (AGFI), comparative fit index (CFI), and root mean square error of approximation (RMSEA) (16). A good fit is indicated by a GFI $\geqq 0.90$, an $\mathrm{AGFI} \geqq 0.90$, a $\mathrm{CFI} \geqq 0.90$, and a RMSEA value $<0.10$ (16).

Reliability was examined by internal consistency and the retest method. In this study, the calculated internal consistency reliability measure was the Cronbach's $\alpha$ coefficient. In most applied studies, the lowest acceptable level of internal consistency reliability is 0.7 for the group level and 0.9 or higher for individual analysis (17). Test-retest reliability of the DILS-C scores was assessed with the intraclass correlation coefficient (ICC).

The Kolmogorov-Smirnov test was used to evaluate normality. Mann-Whitney's $U$ test was used for comparison of gender and year in school in DILS-C scores.

For convergent validity, each scale was scored, and the correlation with each scale score was examined with Spearman's rank correlation coefficient.

Statistical tests except for the confirmatory factor analysis were performed using SPSS Statistics (20, IBM Corp). Significant levels were set at $p<0.05$.
Table 1. Basic characteristics of the 953 Japanese college athletes categorized by gender.

\begin{tabular}{|c|c|c|c|}
\hline & $\begin{array}{c}\text { All } \\
(n=953)\end{array}$ & $\begin{array}{c}\text { Men } \\
(n=684)\end{array}$ & $\begin{array}{l}\text { Women } \\
(n=269)\end{array}$ \\
\hline & \multicolumn{3}{|c|}{ Mean (SD) } \\
\hline Age in years & $20.0(1.1)$ & $20.0(1.2)$ & $20.0(1.1)$ \\
\hline Body height in $\mathrm{cm}$ & $170.8(8.7)$ & $174.2(6.7)$ & $162.2(7.2)$ \\
\hline Body weight in kg & $66.5(12.6)$ & 70.7 (11.7) & $55.8(7.2)$ \\
\hline \multirow[t]{2}{*}{ BMI, $\mathrm{kg} / \mathrm{m}^{2}$} & $22.7(2.9)$ & $23.3(3.0)$ & $21.2(1.8)$ \\
\hline & \multicolumn{3}{|c|}{ Number (\%) } \\
\hline \multicolumn{4}{|l|}{ School year } \\
\hline Freshman & $324(34.0)$ & $238(34.8)$ & $86(32.0)$ \\
\hline Other & $629(66.0)$ & $446(65.2)$ & $183(68.0)$ \\
\hline \multicolumn{4}{|l|}{ Living type $^{1}$} \\
\hline Home & $55(5.8)$ & $35(5.1)$ & $20(7.4)$ \\
\hline Living alone & $687(72.1)$ & $502(73.4)$ & $185(68.8)$ \\
\hline Dormitory & $193(20.2)$ & $139(20.3)$ & $54(20.1)$ \\
\hline Other & $18(1.9)$ & $8(1.2)$ & $10(3.7)$ \\
\hline \multicolumn{4}{|l|}{ Competition type $^{2}$} \\
\hline Team event & $538(56.5)$ & $424(62.0)$ & $114(42.4)$ \\
\hline Individual event & $415(43.5)$ & $260(38.0)$ & $155(57.6)$ \\
\hline
\end{tabular}

All items are self-reported.

${ }^{1}$ Regarding living type, we asked participants to respond from 4: home, living alone, dormitory and other.

${ }^{2}$ An individual event involves competitors performing one at a time. A team event is a competition between groups of two or more people. Team events include ice hockey, American football, soccer, softball, basketball, volleyball, handball, rugby, lacrosse, baseball, semi-rigid baseball, and water polo. Individual events include ice skating, archery, orienteering, cycling, skiing, dancing, triathlon, badminton, lifesaving, rifle shooting, Japanese archery, swimming, karate, kendo, tennis, aikido, judo, Shorinji kempo, gymnastics, lawn tennis, equestrian events, and track and field.

\section{RESULTS}

In the present study, 953 subjects participated, which included 684 men (71.9\%; age: mean $=20.0 \mathrm{y}, \mathrm{SD}=$ $1.1)$ and 269 women $(28.1 \%$; age: mean $=19.9 \mathrm{y}, \mathrm{SD}=$ 1.1) (Table 1). The characteristics of the 953 college athletes categorized by competition type are shown in Table 2. The competition type was classified into team event and individual event. An individual event involves competitors performing one at a time (including: ice skating, archery, orienteering, cycling, skiing, dancing, triathlon, badminton, lifesaving, rifle shooting, Japanese archery, swimming, karate, kendo, tennis, aikido, judo, Shorinji kempo, gymnastics, lawn tennis, equestrian, athletics). A team event is a competition between groups of two or more people (including: ice hockey, American football, soccer, softball, basketball, volleyball, handball, rugby, lacrosse, rigid baseball, semi-rigid baseball, water polo).

In the DILS-C in Japanese college athletes, as a result of exploratory factor analysis that assumed a two-factor structure of communicative literacy and critical liter- 
Table 2. The Cronbach's alpha coefficient in the dietary information literacy scale for competition in Japanese college athletes.

\begin{tabular}{|c|c|c|c|c|c|}
\hline \multirow{2}{*}{\multicolumn{2}{|c|}{ Item }} & \multirow{2}{*}{ Mean } & \multirow{2}{*}{ (SD) } & \multicolumn{2}{|c|}{ Factor loadings } \\
\hline & & & & Factor I & Factor II \\
\hline \multicolumn{6}{|c|}{ Factor I: Communicative literacy (Cronbach’s $\alpha=0.84$ ) } \\
\hline 2 & $\begin{array}{l}\text { You can pick out what you want from a lot of knowledge and } \\
\text { information. }\end{array}$ & 3.6 & $(1.0)$ & 0.86 & -0.11 \\
\hline 3 & $\begin{array}{l}\text { You can understand the knowledge and information you have } \\
\text { seen and heard. }\end{array}$ & 3.9 & $(0.8)$ & 0.84 & -0.11 \\
\hline 1 & $\begin{array}{l}\text { You can collect knowledge and information from various } \\
\text { sources. }\end{array}$ & 3.7 & $(1.0)$ & 0.75 & 0.13 \\
\hline 5 & $\begin{array}{l}\text { You can tell coaches and familiar people your opinions and ideas } \\
\text { about diet. }\end{array}$ & 3.3 & $(1.0)$ & 0.71 & 0.07 \\
\hline 4 & $\begin{array}{l}\text { You can understand the knowledge and information you have } \\
\text { seen and heard, and tell people about it. }\end{array}$ & 3.5 & $(1.0)$ & 0.69 & 0.09 \\
\hline 6 & $\begin{array}{l}\text { You can actually change based on knowledge and information } \\
\text { that you see and hear. }\end{array}$ & 3.3 & $(1.0)$ & 0.59 & 0.15 \\
\hline \multicolumn{6}{|c|}{ Factor II: Critical literacy (Cronbach's $\alpha=0.79$ ) } \\
\hline 2 & You can question reliability. & 3.5 & $(1.0)$ & -0.27 & 0.86 \\
\hline 3 & You can judge to what extent you can trust. & 3.3 & $(1.0)$ & 0.01 & 0.79 \\
\hline 4 & You can ask and check whether it is correct. & 3.5 & $(1.0)$ & 0.05 & 0.77 \\
\hline 5 & $\begin{array}{l}\text { You can find knowledge and information to decide meal and } \\
\text { eating behavior yourself. }\end{array}$ & 3.7 & $(1.0)$ & 0.37 & 0.52 \\
\hline 6 & $\begin{array}{l}\text { You can decide on a plan of action for competition based on } \\
\text { dietary information. }\end{array}$ & 3.4 & $(1.0)$ & 0.33 & 0.43 \\
\hline \multicolumn{4}{|c|}{ Factor contribution (\%) } & 44.2 & 12.1 \\
\hline \multicolumn{4}{|c|}{ Cumulative contribution ratio (\%) } & 44.2 & 56.4 \\
\hline \multicolumn{4}{|c|}{ Eigenvalue } & 4.87 & 1.33 \\
\hline \multicolumn{4}{|c|}{ Factor correlations } & I & 0.53 \\
\hline
\end{tabular}

The subjects were asked the following question: "When you read dietary information for competition, what do you usually think about the following items? Please circle the number of the option that applies to you."

Table 3. Score of dietary information literacy scale for competition in Japanese college athletes.

\begin{tabular}{|c|c|c|c|}
\hline & Communicative literacy & Critical literacy & Total literacy \\
\hline & \multicolumn{3}{|c|}{ The median ( 25 percentile value, 75 percentile value) } \\
\hline All $(n=953)$ & $22.0(19.0,24.0)$ & $18.0(15.0,20.0)$ & $39.0(34.0,43.0)$ \\
\hline \multicolumn{4}{|l|}{ Gender } \\
\hline Men $(n=684)$ & $22.0(19.0,24.0)$ & $18.0(15.0,20.0)$ & $39.0(34.0,43.0)$ \\
\hline Women $(n=269)$ & $21.0(18.0,24.0)$ & $17.0(15.0,20.0)$ & $39.0(33.5,43.0)$ \\
\hline$p^{*}$ & 0.24 & 0.06 & 0.08 \\
\hline \multicolumn{4}{|l|}{ School year } \\
\hline Freshman $(n=324)$ & $21.0(18.0,24.0)$ & $18.0(15.0,20.0)$ & $39.0(33.0,43.8)$ \\
\hline Other $(n=629)$ & $22.0(19.0,24.0)$ & $18.0(15.0,20.0)$ & $39.0(34.0,43.0)$ \\
\hline$p^{*}$ & 0.69 & 0.94 & 0.82 \\
\hline
\end{tabular}

Regarding communicative literacy, the subjects were asked the following question: "When you read the dietary information for competition, what do you usually think about the following items? Please circle the number of the option that applies to you." Regarding critical literacy, the subjects were asked the following question: "Please circle each applicable number in the following items for dietary information for competition you saw or heard." We used the five-point scale; score 1: "I strongly disagree," score 2: "I somewhat disagree," score 3: "I neither disagree nor agree," score 4: "I somewhat agree," score 5: "I strongly agree."

Possible values: Communicative literacy score -6 to 30 points; Critical literacy score -5 to 25 points; Total literacy score11 to 55 points. High scores indicate positive answers.

* The Mann-Whitney test was performed for comparison of gender and year in school. 
acy, 1 item with insufficient aychometric characteristics such as low factor loadings $(<0.40)$ was deleted (Deleted item: critical literacy 1 "I can think whether it applies to me"). In subsequent factor analysis, 11 items of two factors were adopted (Table 2). The cumulative contribution ratio of the two factors was $56.42 \%$. The first factor was termed "communicative literacy" in six items because it was supposed to address communicative literacy, for instance, "You can choose what you want from a lot of information." The second factor was termed "critical literacy" in five items because it was supposed to be evaluative, for instance, "You can have doubts about reliability." Additionally, to examine the DILS-C reliability, we calculated the Cronbach's $\alpha$ coefficient for each factor. That result is shown in Table 3, and the Cronbach's $\alpha$ coefficient for each factor was as follows: communicative literacy $=0.84$, critical liter$\mathrm{acy}=0.79$, total literacy $=0.87$. Thus, reliability was confirmed.

Next, we obtained the GFI $=0.95$, AGFI $=0.92, \mathrm{CFI}=$ 0.95 , and RMSEA $=0.076$, and as a result of the confirmatory factor analysis, we examined the factor model's goodness of fit (Fig. 1). All factor loadings were significant $(p<0.001)$.

In the review of reliability by the retest method, we calculated the intra-class correlation to confirm each factor score's reliability. As a result, moderate consistency was observed; the ICC of communicative literacy score was 0.52 , the critical literacy score was 0.50 , and the literacy score was 0.58 . Temporal stability was confirmed.

Figure S1 (Supplemental Online Material) shows the distribution of the DILS-C scores. As results of the Kolmogorov-Smirnov test, the DILS-C scores did not show normal distribution (communicative literacy: $p<$ 0.001; critical literacy: $p<0.001$; total literacy: $p<$ 0.001). Table 3 presents each factor score by gender and school year. Median scores are as follows: communicative literacy $=22.0$, critical literacy $=18.0$, total literacy $=39.0$. Comparing males and females' scores revealed no significant difference; a difference in critical literacy score and the total score was found, but no difference was found in communicative literacy (commu- nicative literacy: $p=0.24$; critical literacy: $p=0.06$; total literacy: $p=0.08)$. In addition, results showed no significant difference between freshmen and others (communicative literacy: $p=0.69$; critical literacy: $p=0.94$; total literacy: $p=0.82$ ).

The communicative literacy score positively correlated with the healthy eating literacy scale score $(\rho=0.55, p<0.001)$. Critical literacy scores showed low to moderate positive correlation with "judgment" of action skills of information utilization and the healthy eating literacy scale (correlation coefficients were 0.42 , 0.42 , and 0.51: $p<0.001$ ). Total literacy scores showed low to moderate positive correlation with action skills of information utilization and the healthy eating literacy scale (correlation coefficients were 0.44 , and 0.59 : $p<0.001$ ) (Table 4).

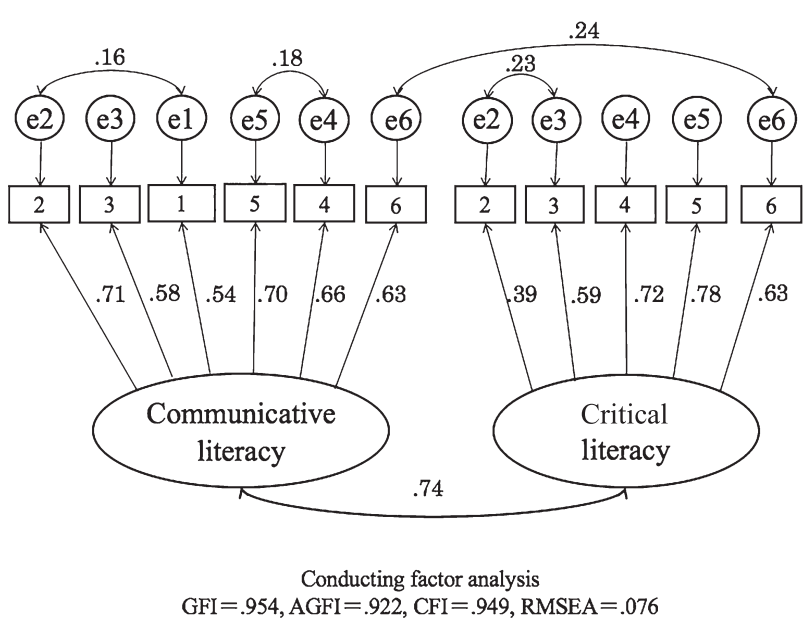

Fig. 1. Confirmatory factor of dietary information literacy scale for competition in Japanese college athletes. Rectangles are observed variables (items), ellipses latent variables (factors), values on the single-headed arrows standardized factor loadings, and values on the double-headed arrows correlation coefficients. GFI: goodness of fit index, AGFI: adjusted GFI, CFI: comparative fit index, RMSEA: root mean square error of approximation.

Table 4. The convergent validity of dietary information literacy scale for competition in Japanese college athletes.

\begin{tabular}{|c|c|c|c|}
\hline & Communicative literacy & Critical literacy & Total literacy \\
\hline \multicolumn{4}{|c|}{ Action skills of information utilization } \\
\hline Collecting ability & 0.31 & 0.35 & 0.36 \\
\hline Power of expression & 0.23 & 0.22 & 0.24 \\
\hline Processing ability & 0.30 & 0.32 & 0.34 \\
\hline Creativity & 0.28 & 0.31 & 0.33 \\
\hline Transmission ability & 0.26 & 0.26 & 0.29 \\
\hline Judgment & 0.29 & $0.42^{*}$ & 0.39 \\
\hline Total & 0.37 & $0.42^{*}$ & $0.44^{*}$ \\
\hline Healthy eating literacy & $0.55^{* *}$ & $0.51^{* *}$ & $0.59 * *$ \\
\hline
\end{tabular}

Values are expressed as Spearman's rank correlation coefficients.

* Low correlation was observed $(p<0.001)$.

*** Moderate correlation was observed $(p<0.001)$. 


\section{DISCUSSION}

The present study was conducted to develop communicative and critical literacy of the DILS-C in college athletes and to examine the scale's reliability and validity. Until now, there has been no dietary information literacy scale for competition in college athletes, although several literacy scales have been developed in Japan (5, 14, 18). Developing the DILS-C will make it possible to discover athletes with low literacy and to obtain clues to promote nutrition education and nutritional guidance for college athletes according to their level of literacy. Moreover, the DILS-C can be used to verify the effectiveness of educational tools aimed at improving literacy in college athlests.

In the confirmatory factor analysis, although item 2 of the critical literacy was low loading, we determined that this model was acceptable. The reason is that the factor loading was significant, that item 2 of the critical literacy was important in the definition of critical literacy, and that indicators of goodness of fit were enough values compared with the previous scales. The previous studies developed instruments of a health literacy among Japanese, such as the healthy eating literacy scale (5) and HLS-14 (14). The internal consistencies of the healthy eating literacy scale and HLS-14 were moderate to high (Cronbach's $\alpha=0.87, \alpha=0.76-0.85$, respectively) $(5,14)$. The factorial validity of those instruments was good (healthy eating literacy scale: $\mathrm{GFI}=0.988, \mathrm{AGFI}=0.957, \mathrm{CFI}=0.990, \mathrm{RMSEA}=0.080$; HLS-14: $\quad$ CFI $=0.912$, RMSEA $=0.082) \quad(5,14)$. The test-retest correlation of the healthy eating literacy scale was acceptable $(r=0.742)(5)$. The test-retest correlation of the DILS-C (communicative ICC $=0.52$, critical $\mathrm{ICC}=0.50$, and all $\mathrm{ICC}=0.58$ ) was lower than that of the previous study (5). This was likely influenced by the longer the test-retest period of the present study than that in the previous research. In present study, the retest period was set at a maximum of $3 \mathrm{wk}$. In addition, the test-retest period of the present study included the term of classes, attendance at classes may have affected literacy. Compared with those instruments (5, 14), both Cronbach's $\alpha$ assessing the internal consistency reliability of the DILS-C (communicative 0.84, critical 0.79) and goodness of fit assessing the factorial validity of DILS-C (GFI $=0.95$, AGFI $=0.92, \mathrm{CFI}=0.95$, RMSEA $=0.076$ ) was generally acceptable. The DILS-C has psychometric properties similar to those of other instruments designed to measure health literacy among Japanese $(5,14)$. Although this model assumed an error covariance between items of different literacy, it was appropriate because both items were applied contents and had similarities.

As a result of examining convergent validity, the healthy eating literacy scale showed moderate correlation with critical literacy, communicative literacy, total literacy in DILS-C. Action skills of information utilization showed significant correlation with critical literacy and total literacy in DILS-C. Since action skills of information utilization are comprehensive concept that does not limit the content of information (15), it is considered that those who have high action skills of information utilization also have high literacy regarding diet. This relationship is supported by a confirmed relationship between health literacy, and knowledge and educational background $(9,19,20)$. Moreover, "collecting ability" and "judgment ability," sub-scales of action skills, showed higher correlation coefficients with each DILS-C than other factors. "Collecting ability" and "judgment ability" are defined as "ability to independently and exhaustively collect necessary information by appropriate means, according to the purpose" and "ability to select the necessary information from a lot of information, judge contents, and extract appropriate information," respectively (15). These sub-scales are closer to the concept of health literacy. The finding is one of the evidences indicating the convergent validity of DILS-C. From the above, we suggest that this scale is usable.

The DILS-C showed no significant difference depending on the school year. Previous studies have reported that literacy scores rise with education $(21,22)$. Although Hardaya et al. reported that literacy scores are higher on average for college students of over $2 \mathrm{y}$, the comparison remains at functional literacy (9), and it is hard to say that similar results are obtained for a high literacy rate in Japanese. In addition, seniors scored highest when nutrition knowledge was compared among college students according to school year, the reason being that they received nutrition classes (23). However, in this study, it seems that most of the participants have the same level of knowledge because they were receiving nutrition lessons in freshmen. From the results reported above and the interrelation between literacy score and knowledge, this study found no difference in literacy scores by school year.

The present study has at least three considerable limitations. First, because the measured self-reported literacy may include skewed literacy influenced by social desirability or self-presentation biases (24), self-reported literacy might not always reflect accurately the actual underlying literacy. Thus, complementary assessment of implicit literacy should be subject for future research. Second, the subjects were not a random selection of Japanese college athletes. In order to recruit the subjects from various sports, only one university was targeted. Therefore, there is a possibility that competitive level and socioeconomic status of the subjects are biased. Further researches are required to involve athletes in a more diverse group. Finally, convergent validity was investigated to assess in relation to other measures; however, predictive validity was not assessed in relation to actual behavior and knowledge, performance. The relationship between dietary behavior should therefore be investigated in a prospective study. To add evidence of DILS-C, further research needs to evaluate the dietary information literacy associated with the dietary behavior.

In conclusion, the present findings confirmed the reliability and factorial validity in communicative and criti- 
cal literacy on the DILS-C in Japanese college athletes. Consequently, this scale is suggested to be usable as a measure for evaluating Japanese college athletes' ability to obtain, understand, and utilize dietary information for competition.

\section{Authorship}

Y.K., N.O., M.O., and I.S. designed for the study. Y.K. and A.K. collected and analyzed the data. Y.K. and M.M. wrote the main manuscript text. All authors reviewed and approved the final manuscript.

\section{Disclosure of state of COI}

This work was supported by Management Expenses Grants from the University of Tsukuba and by Ajinomoto Co., Inc. Miho Ono and Ikuko Sasahara are employees of Ajinomoto Co., Inc. The other authors have no conflicts of interest to declare.

\section{Acknowledgments}

We thank our study participants for their valuable contributions, and students at the University of Tsukuba. We also thank our collaborators. Lastly, we would like to express gratitude to Professor Randeep R. for supporting its composition in English.

\section{Supporting information}

Supplemental online material is available on J-STAGE.

\section{REFERENCES}

1) Heaney S, O'Connor H, Naughton G, Gifford J. 2008. Towards an understanding of the barriers to good nutrition for elite athletes. Int J Sport Sci Coach 3(3): 391401.

2) Hornstrom GR, Friesen CA, Ellery JE, Pike K. 2011. Nutrition knowledge, practices, attitudes, and information scores of Mid-American conference college softball players. Food Nutr Sci 2: 109-117.

3) Zinn C, Schofield G, Wall C. 2006. Evaluation of sports nutrition knowledge of New Zealand premier club rugby coaches. Int I Sport Nutr Exerc Metabolism 16: 214-225.

4) Froiland K, Koszewski W, Hingst J, Kopecky L. 2004. Nutritional supplement use among college athletes and their sources of information. Int J Sport Nutr Exerc Metabolism 14(1): 104-120.

5) Takaizumi K, Harada K, Shibata A, Nakamura Y. 2012. Reliability and validity of the healthy eating literacy scale among Japanese adult: From online web research data. Jpn Soc Health Educ Promot 20(1): 30-40 (in Japanese).

6) World Health Organization. 1998. WHO Health Promotion Glossary. WHO Collaborating Centre for Health Promotion, Department of Public Health and Community Medicine, University of Sydney, NSW.

7) Nutbeam D. 2000. Health literacy as a public health goal: a challenge for contemporary health education and communication strategies into the 21st century. Health Promot Int 15: 259-267.

8) Weiss BD, Hart G, McGee DL, D'Estelle S. 1992. Health status of illiterate adults: relation between literacy and health status among persons with low literacy skills. J Am Board Fam Pract 5(3): 257-264.

9) Hansen H, Shneyderman Y, Belcastro P. 2015. Investigating the association of health literacy with health knowledge and health behavior outcomes in a sample of urban community college undergraduates. Am J Health Educ 46(5): 274-279.

10) Nakanishi A, Eto K, Takemi Y. 2012. Development of the dietary-related media literacy scale among junior high school students. Jpn Soc Health Educ Promot 20(3): 207-220 (in Japanese).

11) Reynolds JS, Treu JA, Njike V, Walker J, Smith E, Katz CS, Katz DL. 2012. The validation of food label literacy questionnaire for elementary school children. J Nutr Educ Behav 44(3): 262-265.

12) Ickes MJ, Cottrell R. 2010. Health literacy in college students. J Am Coll Health 58(5): 491-498.

13) Kakutani Y, Koiwa A, Kamiya S, Ono M, Sasahara I, Omi N. 2019. Why do athletes choose dietary supplements? Reliability and validity of the Dietary Supplement Choice Questionnaire (DSCQ) among Japanese college athletes. J Nutr Sci Vitaminol 65(4): 343-348.

14) Suka M, Odajima T, Kasai $M$, Igarashi A, Ishikawa $H$, Kusama M, Nakayama T, Sumitani M, Sugimori H. 2013. The 14-item health literacy scale for Japanese adults (HLS-14). Environ Health Prev Med 18(5): 407415.

15) Takahira M, Sakamoto A, Mori T, Sakamoto K, Adachi N, Suzuki K, Katsuya N, Kobayashi K, Kimura F, Hatano K, Sakamoto T. 2001. Construction of a scale for the skills of practical use of information and its reliability and validity. Jpn J Educ Technol 24(4): 247-256 (in Japanese).

16) Kline RB. 2011. Principles and Practice of Structural Equation Modeling, 3rd ed (Kline BR, ed). Guilford Press, New York.

17) Nunnally J, Bernstein I. 1994. Psychometric Theory, 3rd ed. McGraw-Hill, New York.

18) Tokuda Y, Okubo T, Yanai H, Doba N, Paasche-Orlow MK. 2010. Development and validation of a 15-item Japanese health knowledge test. J Epidemiol 20(4): 319328.

19) Bains SS, Egede LE. 2011. Associations between health literacy, self-care behaviors, and glycemic control in low income population with type 2 diabetes. Diabetes Technol Ther 13(3): 335-341.

20) Ishikawa H, Takeuchi T, Yano E. 2008. Measuring functional, communicative, and critical health literacy among diabetic patients. Diabetes Care 31(5): 874-879.

21) Tokuda Y, Doba N, Butler JP, Paasche-Orlow MK. 2009. Health literacy and physical and psychological wellbeing in Japanese adults. Patient Educ Couns 75(3): 411417.

22) Furuya Y, Kondo N, Yamagata Z, Hashimoto H. 2015. Health literacy, socioeconomic status and self-rated health in Japan. Health Promot Int 30(3): 505-513.

23) Ozdoğan Y, Ozcelik AO. 2011. Evaluation of the nutrition knowledge of sports department students of universities. J Int Soc Sports Nutr 8(11): 11.

24) Greenwald AG, Nosek BA, Banaji MR. 2003. Understanding and using the implicit association test: I. An improved scoring algorithm. J Pers Soc Psychol 85(2): 197-216. 